\title{
Analisis Pengendalian Kualitas Proses Produksi Kue Lapis Kukus Surabaya Berdasarkan Metode Six Sigma
}

\author{
ARDi KuRNiAWAN, SEDIONO, FAuZEA AdinNA \\ Departemen Matematika, Fakultas Sains dan Teknologi, Universitas Airlangga \\ Kampus C Unair Jalan Mulyorejo, Surabaya \\ Email: ardik2008@gmail.com
}

\begin{abstract}
ABSTRAK
Salah satu kue yang cukup dikenal dan ramai di Surabaya saat ini adalah kue Lapis Kukus Surabaya yang diproduksi oleh CV. Alam Boga Raya. Agar tetap bertahan dan tumbuh menjadi perusahaan industri yang besar CV. Alam Boga Raya perlu memperhatikan kualitas produksi dengan selalu menekan jumlah cacat produk menuju zero defect. Salah satu metode yang bisa digunakan untuk mengendalikan kualitas produksi atau quality control adalah metode Six Sigma. Penelitian ini bertujuan untuk menganalisis kualitas produksi dengan menggunakan metode Six Sigma yang terdiri dari tahap Define, Measure, Analyze, Improve and Control (DMAIC). Metode tersebut digunakan untuk menentukan arus produksi, melakukan pengukuran terkait proses produksi, menganalisis jenis kecacatan, menentukan faktor penyebab cacat dan melakukan usulan perbaikan. Variabel yang digunakan dalam penelitian ini adalah empat kategori cacat produk yaitu kue pendek, kue rapuh, kue pisah dan kue mentah. Penelitian ini menggunakan data sekunder jumlah produksi bruto dan data jumlah cacat sedangkan untuk data primer dilakukan wawancara dengan pihak perusahaan untuk mendapatkan data yang terkait dengan proses produksi meliputi penyediaan bahan baku, proses produksi dan faktor penyebab kecacatan. Berdasarkan hasil analisis Six Sigma diketahui bahwa perusahaan berada pada level $4,46 \sigma$ dan kategori cacat yang banyak dialami oleh perusahaan adalah kue mentah yang disebabkan oleh ketidakstabilan mesin steam.
\end{abstract}

Kata Kunci : Lapis Kukus Surabaya, Kontrol Kualitas, Six Sigma, DMAIC

\section{PENDAHULUAN}

Kue merupakan salah satu jenis makanan ringan yang dapat dinikmati masyarakat Indonesia. Kue terdiri dari berbagai jenis, warna, aroma dan rasa. Bahan utama dari kue adalah tepung, baik tepung beras, tepung sagu, tepung terigu, maupun tepung tapioka. Salah satu kue yang dapat dinikmati banyak orang khususnya masyarakat Surabaya adalah kue Lapis Kukus Surabaya. Hal tersebut dibuktikan dengan banyaknya outlet yang sudah dibuka yaitu 32 outlet dalam kurun waktu 2 tahun.

CV. Alam Boga Raya adalah perusahaan yang memproduksi Kue Lapis Kukus Surabaya menyadari banyaknya persaingan dalam penjualan kue yang sejenis. Oleh karena itu perusahaan tersebut telah membuka sebanyak 32 outlet dalam kurun waktu 2 tahun dan selalu menjaga kualitas kue lapis kukus yang diproduksinya.

Metode six sigma merupakan salah satu metode pengendalian kualitas yang memiliki metodologi terstruktur untuk memperbaikiproses. Pendekatan DMAIC merupakan salah satu pendekatan six sigma yang dapat memberikan suatu arahan perbaikan yang sistematis. Beberapa penelitian yang menggunakan metode six sigma dengan pendekatan DMAIC, antara lain Wibisono dan Suteja (2013) yang mengemukakan bahwa aplikasi dan potensi DMAIC Six Sigma dalam proyek perbaikan mutu untuk satu jenis produk merupakan pendekatan dan metode yang efektif dalam kegiatan produksi dan berhasil memperbaiki kualitas. Studi yang dilakukan oleh Park (2002) mengekspresikan bahwa perusahaan dapat menerapkan strategi bisnis untuk meningkatkan kinerja perusahaan dengan metode Six Sigma.

Berdasarkan uraian tersebut akan dilakukan penelitian tentang pengendalian kualitas produksi di CV Alam Boga Raya menggunakan metode Six Sigma. Penelitian tersebut 


\section{Ardi Kurniawan, dkk.}

diharapkan dapat dijadikan masukan untuk mengendalikan jumlah produk cacat sehingga dapat meningkatkan kualitas perusahaan hingga ke taraf 6 sigma atau disebut Six Sigma.

\section{TINJAUAN PUSTAKA}

\section{Metode Six Sigma}

Six sigma merupakan sebuah metodologi terstruktur untuk memperbaiki proses yang difokuskan pada usaha mengurangi variasi proses (process variances) sekaligus mengurangi cacat (produk atau jasa yang diluar spesifikasi) dengan menggunakan statistik dan problem solving tools secara intensif. Six sigma bertujuan untuk menemukan dan mengurangi faktorfaktor penyebab kecacatan dan kesalahan, mengurangi waktu siklus dan biaya operasi, meningkatkan produktivitas dan memenuhi kebutuhan pelanggan dengan lebih baik.

Standar six sigma dalam proses produksi dikenal dengan istilah defectively rate of process dengan nilai sebesar 3,4 defektif di setiap juta unit per proses. Artinya, dalam satu juta unit per proses hanya diperkenankan mengalami kegagalan atau cacat produk sebanyak 3,4 unit per proses. Berikut adalah tabel yang menunjukkan tingkat kualitas sigma per satu juta produk.

Tabel 1. Tingkat Kualitas Six Sigma

\begin{tabular}{|c|c|c|}
\hline $\begin{array}{l}\text { Yield(probabilitas tanpa } \\
\text { cacat) }\end{array}$ & $\begin{array}{l}\text { Defect Per Million Opportunity } \\
\text { (DPMO) }\end{array}$ & $\begin{array}{l}\text { Level } \\
\text { Sigma }\end{array}$ \\
\hline $30,9 \%$ & 690.000 & 1 \\
\hline $69,2 \%$ & 308.000 & 3 \\
\hline $93,3 \%$ & 66.800 & 4 \\
\hline $99,4 \%$ & 6.210 & 5 \\
\hline $99,98 \%$ & 320 & 6 \\
\hline $99,9997 \%$ & 3,40 & \\
\hline
\end{tabular}

(Sumber : Syukron dan Kholil, 2013)

Metode yang paling umum digunakan untuk mengukur penerapan six sigma di dalam sebuah organisasi adalah konsep DMAIC. Tahap DMAIC dimulai dengan proses Identifikasi (Define), Pengkuran (Measure), Analisis (Analyze), Perbaikan (Improve), Pengendalian (Control) (Tannady, 2015).

\section{Analisis Kemampuan Proses}

Analisis Kemampuan Proses merupakan suatu studi untuk menaksir kemampuan proses dalam bentuk distribusi probabilitas yang mempunyai bentuk, rata-rata (mean), dan penyebaran (simpangan baku). Analisis kemampuan proses diantaranya digunakan untuk mengukur kinerja proses atau untuk melihat apakah kemampuan proses sudah memenuhi spesifikasi yang diharapkan (Ariani, 2004). Nilai yang sering dipakai untuk mengetahui kemampuan proses adalah nilai Capability process $(\mathrm{Cp})$ dan Capability process kane (Cpk). Semakin tinggi nilai indeks kemampuan suatu proses, maka semakin sedikit produk yang berada diluar batas-batas spesifikasi

Kriteria-kriteria yang digunakan dalam penentuan $\mathrm{Cp}$ dan $\mathrm{Cpk}$ adalah sebagai berikut :

a) Untuk Cp

$\mathrm{Cp}>1$ berarti kemampuan potensial suatu proses baik (capable) ;

$\mathrm{Cp}<1$ berarti kemampuan potensial suatu proses tidak baik (not capable); dan

$\mathrm{Cp}=1$ berarti kemampuan potensial proses sama dengan spesifikasi konsumen.

b) Untuk Cpk

Cpk $\geq 1$ berarti kemampuan potensial mutlak suatu proses baik (capable); dan

$\mathrm{Cp}<1$ berarti kemampuan potensial mutlak suatu proses tidak baik (not capable)

Statistika, Vol. 18, No. 1, Mei 2018 
Terdapat 3 (tiga) asumsi untuk melakukan Analisis Kemampuan Proses, yaitu :

1) Proses berada dalam batas kendali statistik.

2) Distribusi proses adalah distribusi normal.

3) Variabilitas proses tidak disebabkan oleh sebab khusus, tetapi disebabkan oleh sebab umum.

\section{METODE PENELITIAN}

\section{Sumber Data}

Data yang digunakan dalam penelitian ini merupakan data sekunder tentang produk kue Lapis Kukus Surabaya dari CV Alam Boga. Data yang diperoleh merupakan data jumlah produksi dan jumlah produk cacat pada bulan Oktober-Desember 2016 yang diperoleh dari lembar pemeriksaan dibagian pengendalian kualitas pada setiap shift. Data yang diperoleh adalah data hasil wawancara dan data sekunder yang terdiri dari 161 data jumlah produksi bruto dan 161 data jumlah cacat.

\section{Variabel Penelitian}

Variabel yang digunakan dalam penelitian ini adalah variabel jenis cacat pada kue Lapis Kukus Surabaya. Jenis cacat yang diamati adalah kue pendek (C1), kue rapuh (C2), kue pisah (C3), dan kue mentah (C4).

\section{Langkah Penelitian}

Langkah - langkah analisis data yang digunakan untuk mencapai tujuan penelitian antara lain sebagai berikut :

1) Mendeskripsikan jumlah cacat pada produksi kue Lapis Kukus Surabaya di CV. Alam Boga Raya dengan langkah-langkah sebagai berikut:

a. Membuat tabel jumlah cacat per bulan.

b. Membuat tabel jumlah cacat per kategori cacat.

2) Menganalisis pengendalian kualitas dengan menggunakan metode Six Sigma, adapun langkah-langkahnya sebagai berikut :

a. Mengidentifikasi masalah pada proses produksi lampu pijar, dengan langkah :

i. Membuat diagram Supplier-Input-Process-Output-Customers (SIPOC).

ii. Menentukan karakteristik kerusakan/cacat produk.

b. Melakukan pengukuran terhadap data cacat, dengan langkah-langkah :

i. Membuat peta kendali C.

ii. Melakukan iterasi berulang pada pembuatan peta kendali C apabila proses masih Out Control.

iii. Menguji kenormalan data menggunakan software Minitab.

iv. Menganalisis kemampuan proses berdasaran nilai Capability Process (Cp) dan Capability Process Kane (Cpk).

v. Menghitung level sigma dengan mengkonversikan nilai DPMO menggunakan tabel konversi Six Sigma.

c. Mengetahui urutan jenis cacat yang paling dominan dengan menggunakan Diagram Pareto.

d. Memberikan usulan perbaikan pada proses produksi Lapis Kukus Surabaya, dengan membuat Diagram Sebab-Akibat berdasarkan jenis cacat dominan yang dihasilkan pada Diagram Pareto. 


\section{Ardi Kurniawan, dkk.}

\section{PEMBAHASAN}

Jumlah kecacatan produk yang dialami oleh CV. Alam Boga Raya naik turun setiap bulan selama triwulan terakhir pada tahun 2016. Berikut merupakan tabel jumlah produksi bruto dan jumlah cacat kue lapis kukus Surabaya selama bulan Oktober, Nopember dan Desember 2016 :

Tabel 2. Jumlah Produksi Bruto dan Jumlah Cacat

\begin{tabular}{|l|l|l|}
\hline & Jumlah Produksi Bruto & Jumlah Cacat \\
\hline Oktober & 185114 & 3292 \\
\hline Nopember & 194592 & 2485 \\
\hline Desember & 241836 & 2876 \\
\hline
\end{tabular}

Berdasarkan Tabel 1 dapat diketahui jumlah produksi bruto keseluruhan (U) adalah sebesar 621542 dan jumlah maksimum berada pada bulan Desember yaitu sebanyak 241836 sedangkan jumlah cacat maksimum berada pada bulan Oktober yaitu sebanyak 3292. Jumlah cacat untuk setiap kategori cacat diberikan pada tabel 2 di bawah ini :

Tabe1 3. Jumlah Cacat Untuk Setiap Kategori Cacat

\begin{tabular}{|l|l|}
\hline Kategori Cacat & Jumlah Cacat \\
\hline Kue Pendek & 2009 \\
\hline Kue Rapuh & 1515 \\
\hline Kue Pisah & 1666 \\
\hline Kue Mentah & 3454 \\
\hline
\end{tabular}

Tahapan dalam Six Sigma dalam memperbaiki proses produksi kue kukus Surabaya yang difokuskan pada usaha mengurangi variasi proses (process variances) sekaligus mengurangi cacat (produk atau jasa yang diluar spesifikasi). Six sigma terdiri dari tahapan yang disebut define, measure, analyze, improve dan control (DMAIC). Selanjutnya ke lima tahapan tersebut diuraikan sebagai berikut :

\section{i. Define}

Pada tahap ini dilakukan pengidentifikasian proses produksi secara garis besar. Tujuan dari tahap ini adalah agar dapat mengetahui aliran kerja dari input yang digunakan sampai produk dihasilkan. Dengan demikian dapat dilakukan perbaikan-perbaikan yang diperlukan agar dapat meningkatkan kualitas produk. Diagram SIPOC pada produksi kue lapis kukus di CV. Alam Boga Raya dapat dilihat pada sebagai berikut :

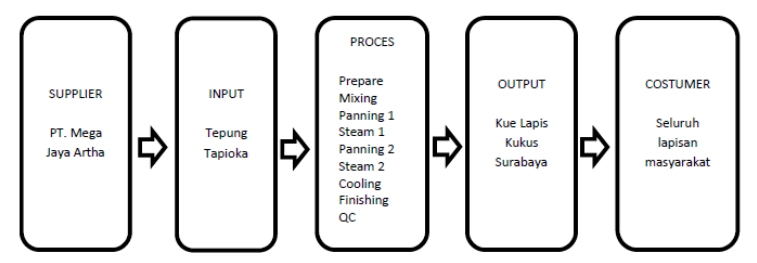

Gambar 1. Diagram SIPOC

Produk yang sampai di tangan pelanggan merupakan produk yang telah diuji dengan memperhatikan batasan yang ditentukan oleh perusahaan sehingga menghasilkan produk berkualitas yang tidak mengalami kerusakan. Karakteristik kerusakan produk sesuai dengan 
kategori yang telah ditentukan oleh perusahaan meliputi kue pendek, kue rapuh, kue pisah dan kue mentah.

ii. Measure

Measure adalah langkah selanjutnya dalam metode DMAIC yang merupakan tindak lanjut dari langkah define. Measure merupakan tahap pengukuran yang dibagi menjadi beberapa tahap. Apabila dalam proses pengukuran tidak memenuhi kriteria peta kendali, maka dilakukan iterasi berulang sampai memenuhi kriteria peta kendali yaitu proses terkendali.

a. Peta Kendali C

Peta kendali $\mathrm{C}$ digunakan untuk pengendalian jumlah cacat per unit. Perhitungan Batas Kontrol Atas (UCL) dan Batas Kontrol Bawah (LCL) untuk peta kendali C berdasarkan data awal adalah sebagai berikut:

Nilai $\sum_{i=1}^{n} C_{i}=8653$ dan $\mathrm{n}=161$, sehingga $\bar{C}=53,74534$ dengan demikian UCL dan LCL masing-masing :

$U C L=\bar{C}+3 \sqrt{\bar{C}}=75,74$ dan $L C L=\bar{C}-3 \sqrt{\bar{C}}=31,75$

Hasil ploting data jumlah cacat per unit serta nilai UCL dan LCL yang diperoleh yaitu:

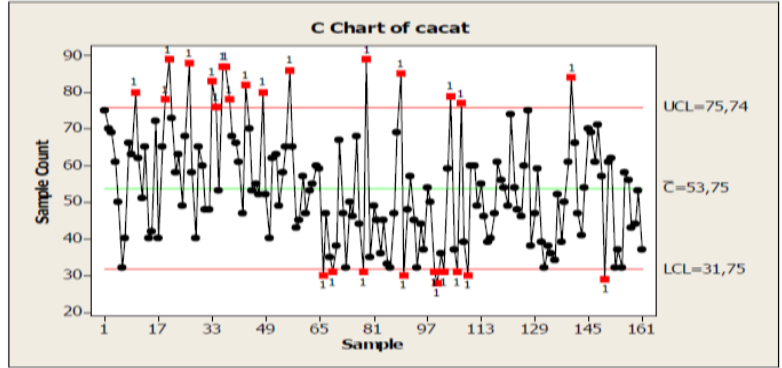

Gambar 2. Peta Kendali C Data Awal

Berdasarkan peta kendali C pada Gambar 2, terdapat beberapa titik pengamatan yang berada di luar batas kendali. Hal tersebut dianggap sebagai proses yang tak terkendali (out control) karena terdapat 27 titik pengamatan yang berada diluar batas kendali. Dengan demikian perlu dibuat peta kendali $\mathrm{C}$ lagi dengan tidak mengikutsertakan 27 titik pengamatan yang di luar batas kendali. Menggunakan cara yang sama dengan pembuatan peta kendali $\mathrm{C}$ yang pertama, hasil pembuatan peta kendali $\mathrm{C}$ yang kedua yaitu :

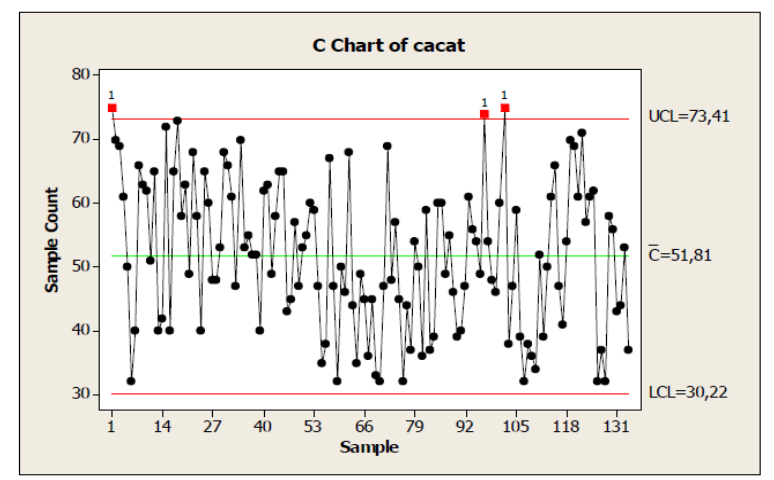

Gambar 3. Peta Kendali C yang Kedua

Seperti halnya peta kendali C Gambar 2, pada Gambar 3 ini nampak masih ada 3 data pada Peta Kendali $\mathrm{C}$ yang diluar batas kendali. Sehingga proses diulang kembali hingga diperoleh peta kendali dengan semua data in controll. Setelah dilakukan perulangan pembuatan peta kendali C sebanyak 4 kali diperoleh peta kendali dengan semua data in controll. UCL dan LCL 


\section{Ardi Kurniawan, dkk.}

pada peta kendali $\mathrm{C}$ yang keempat tersebut masing-masing adalah : UCL $=72,53$ dan $\mathrm{LCL}=$ 29,64 .

b. Uji Normalitas Data

Setelah proses diketahui sudah terkendali (in control), maka perlu dilakukan uji normalitas untuk mengetahui kenormalan data menggunakan software Minitab. Berikut adalah hipotesis uji normalitas dengan $a=5 \%$.
HO :
Data Berdistribusi Normal
H1 : Data Tidak Berdistribusi Normal

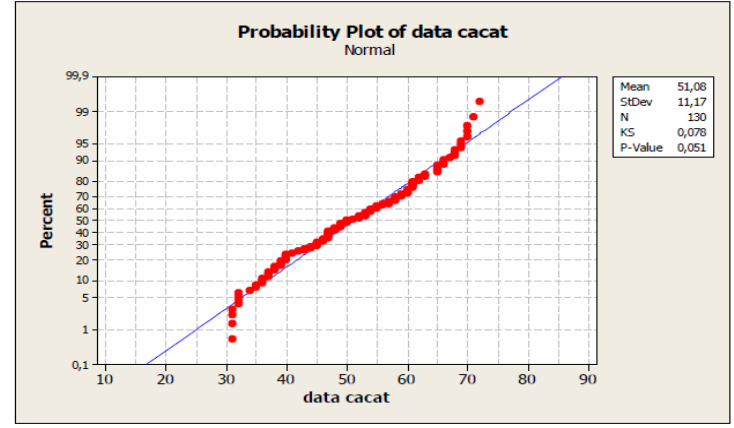

Gambar 4. Uji Distribusi Normal

Berdasarkan gambar 4.8 didapatkan hasil normalitas menggunakan uji Kolmogorov-Smirnov, hasil $\mathrm{p}$-value $=0,051>\mathrm{a}=0,05$. Dari hasil tersebut didapatkan keputusan terima Ho yaitu data berdistribusi normal.

c. Analisis Kemampuan Proses

Karena proses sudah terkendali dan data juga berdistribusi normal maka proses selanjutnya dapat dilakukan yaitu analisis kemampuan proses.

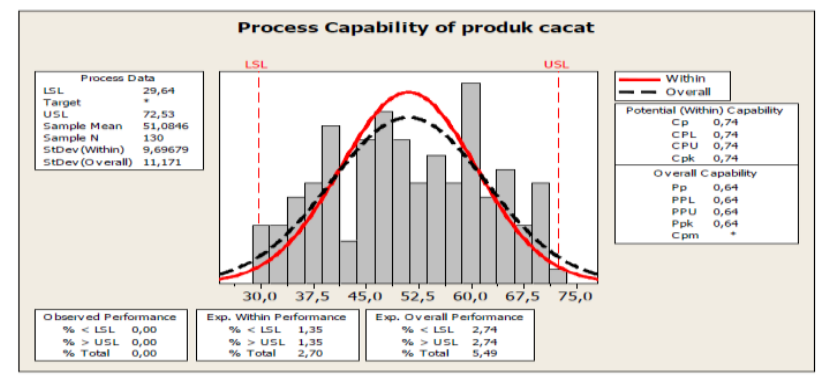

Gambar 5. Analisis Kemampuan Proses

Berdasarkan Gambar 5 diperoleh nilai Cp sebesar 0,74 dan nilai Cpk sebesar 0,74. Nilai Cp $<1$ menunjukkan bahwa proses produksi belum kapabel. Nilai Cpk $<1$ menunjukkan bahwa proses produksi masih menghasilkan produk yang belum sesuai dengan spesifikasi.

d. Nilai Sigma

Nilai sigma merupakan suatu indikator dari tingkat variasi produk. Ukuran sigma diperoleh dengan mengonversi nilai DPMO ke dalam tabel six sigma. Berikut adalah perhitungan nilai sigma :

Total Opportunities $(\mathrm{TOP})=\quad \mathrm{U} \times \mathrm{OP}=621.542 \times 4=2.486 .168$

Defect Per Opportunities $(\mathrm{DPO})=\mathrm{D} / \mathrm{TOP}=8.653 / 2.486 .168=0,00348$

Defect Per Million Opportunities $=$ DPO x $1.000 .000=0,00348 \times 1.000 .000=3.480$

Nilai Sigma perusahaan : 
$\frac{6210-3480}{3480-320}=\frac{4-x}{x-5}$

$x=4,46 \sigma$

Berdasarkan hasil tersebut menunjukkan bahwa kinerja perusahaan kue Lapis Kukus Surabaya yang diproduksi oleh CV. Alam Boga Raya Cemerlang berada pada level 4,46o dengan nilai DPMO 3480.

iii. Analyze

Tahap ini dilakukan untuk mengetahui faktor yang mempengaruhi yang dianggap paling dominan agar dapat dilakukan perbaikan terhadap proses yang ada menggunakan diagram pareto. Berikut Diagram Pareto untuk kue lapis kukus Surabaya:

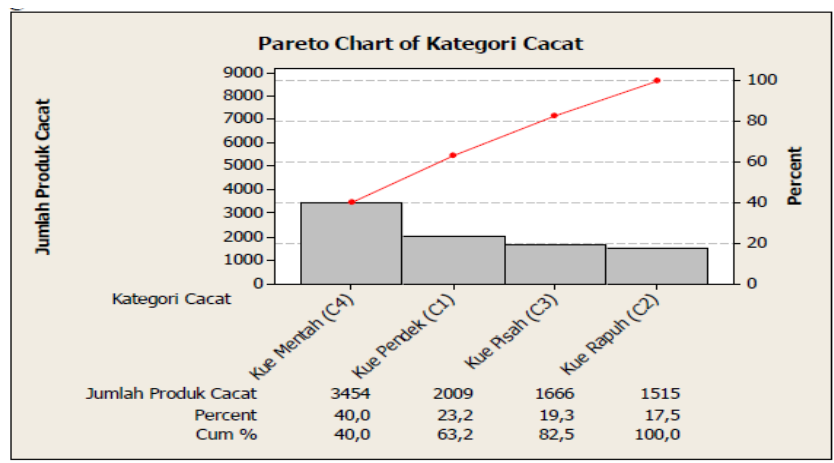

Gambar 6. Diagram Pareto

Pada Gambar 6 dapat dilihat bahwa kue mentah merupakan penyebab banyak cacat terbesar, yaitu sebanyak $40 \%$.

\section{iv. Improve}

Setelah diketahui jenis cacat yang mendominasi jumlah produk cacat maka selanjutnya dapat diteliti penyebab yang mengakibatkan terjadinya produk cacat. Alat yang dapat digunakan untuk mengetahui penyebab terjadinya produk cacat menggunakan diagram sebab akibat untuk dapat dilakukan perbaikan (improve).

1. Diagram Sebab-Akibat

Setelah dilakukan wawancara diketahui bahwa cacat kue Lapis Kukus Surabaya disebabkan oleh beberapa faktor, yaitu manusia, mesin, bahan baku, dan lingkungan. Berikut disajikan Diagram Sebab-Akibat khususnya untuk cacat yang disebabkan oleh kue mentah :

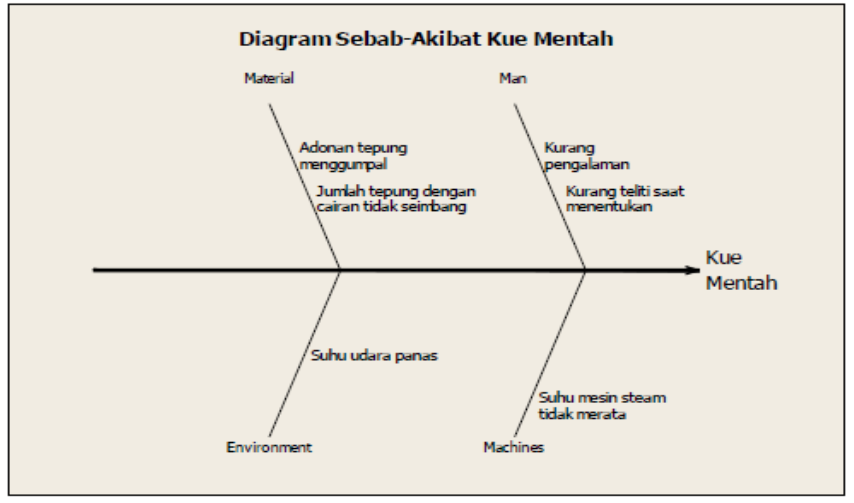

Gambar 7. Diagram Sebab Akibat Kue Mentah

Setelah mengetahui penyebab kecacatan atas suatu produk, maka disusun suatu rekomendasi atau usulan tindakan perbaikan secara umum dalam upaya menekan tingkat kerusakan produk sebagai berikut: 


\section{Ardi Kurniawan, dkk.}

1. Faktor Manusia

Perbaikan untuk faktor manusia dapat dilakukan dengan cara :

a. Membuat suatu bagian kerja baru yang bertugas melakukan pengawasan dan pengecekan ulang terhadap kinerja karyawan sehingga dapat mengurangi kesalahan yang disebabkan oleh humanerror.

b. Meningkatkan pelatihan agar karyawan lebih terampil dalam menjalankan tugas.

2. Faktor Metode

Perbaikan untuk faktor metode dapat dilakukan dengan cara membentuk tim ahli dari beberapa karyawan untuk lebih memperhatikan proses mixing. Perhatian pada proses mixing penting, karena inti dari kesempurnaan texture dan rasa kue adalah tercampurnya semua adonan secara merata dan sempurna.

\section{Faktor Material}

Perbaikan untuk faktor material dapat dilakukan dengan cara :

a. Memeriksa kembali bahan baku yang diterima dari pemasok dengan lebih teliti dan memeriksa apakah sudah memenuhi spesifikasi yang ditentukan atau tidak.

b. Memisahkan bahan baku yang rusak dengan bahan baku yang berkualitas baik.

4. Faktor Mesin

Perbaikan untuk faktor mesin dapat dilakukan dengan cara :

a. Melakukan pengecekan kesiapan mesin dengan teliti sebelum digunakan dan juga ketika selesai digunakan.

b. Melakukan perawatan mesin secara rutin, tidak hanya dilakukan ketika mesin mengalami kerusakan (preventive maintenance).

c. Menyediakan suku cadang mesin yang sering rusak agar tidak menghambat proses produksi.

5. Faktor Lingkungan

Perbaikan untuk faktor lingkungan dapat dilakukan dengan cara menambah fasilitas di ruang produksi agar memberikan kenyamanan dalam bekerja.

\section{KESIMPULAN}

Berdasarkan hasil analisis dan pembahasan yang dilakukan terhadap data cacat produk maka dapat diperoleh kesimpulan sebagai berikut :

1. Kegagalan atau kecacatan produksi paling tinggi kue Lapis Kukus Surabaya yang diproduksi oleh CV. Alam Boga Raya Cemerlang adalah berada pada bulan Oktober 2016 yaitu sebesar 3454 yang disebabkan oleh mentah. Hal tersebut terjadi karena masih sederhananya mesin untuk proses steam sehingga seringkali suhu tidak merata.

2. Berdasarkan jumlah cacat yang dialami oleh kue Lapis Kukus Surabaya, dengan menggunakan metode Six Sigma dapat diketahui bahwa perusahaan memiliki nilai DPMO 3480 dan berada pada level 4,46 sigma atau level 4,46 $\sigma$.

\section{DAFTAR PUSTAKA}

Ariani, D.W., 2004, Pendekatan Kualitas Statistik (Pendekatan Kuantitatif dalam Manajemen Kualitas), Andi, Yogyakarta.

Park, S.H., 2002, Six Sigma For Productivity Improvement: Korean Business Corporations, Productivity Journal, Vol. 43, pp.: 173 - 183.

Syukron, A. dan Kholil M., 2013, Six Sigma Quality for Business Improvement, Graha Ilmu, Yogyakarta. 
Tannady, H., 2015, Pengendalian Kualitas, Graha Ilmu, Yogyakarta.

Wibisono, Y. Suteja, T., 2013, Implementasi Metode DMAIC-Six Sigma dalam Perbaikan Mutu di Industri Kecil Menengah: Studi Kasus Perbaikan Mutu Produk Spring Adjuster di PT. X, Prosiding Seminar Nasional IENACOISSN: 2337-4349. 